\title{
Rainfall Attenuation and Rainfall Rate Measurements in Malaysia Comparison with Prediction Models
}

\author{
Mandeep Singh Jit Singh, Syed Idris Syed Hassan and Mohd Fadzil Ain \\ School of Electrical and Electronic Engineering \\ University Science Malaysia, 14300 Nibong Tebal, Seberang Perai Selatan, Penang
}

\begin{abstract}
Attenuation due to rain is a primary cause of communication impairment on satellite-earth paths, especially above $10 \mathrm{GHz}$. Rainfall is a serious source of attenuation at such a frequency. This paper presents the characteristics of rain distribution in USM based on measured one minute rain rate. For attenuation of rain, predictions models like ITU and VIHT (Variable Isotherm Height Technique) model were used to estimate the effect of rain on Ku band signals. Data of rain attenuation and rainfall rates collected at USM are estimated and compared with the predicted models. The ITU model followed closely to the measured rainfall rate and attenuation data whereas the VIHT models overestimated the measured rainfall rate and attenuation data.
\end{abstract}

Key words: Satellite communication, rainfall rate, rainfall attenuation

\section{INTRODUCTION}

Rainfall attenuation has long been recognized as the main source of atmospheric attenuation in terrestrial and satellite links beyond 10GHz. Major efforts have been made during the last three decades to characterize the statistical and dynamic aspects of rainfall rate and rain attenuation ${ }^{[1]}$. Knowledge of the rain attenuation at such frequency range is desirable in the planning of a reliable communication system at any location. This will be more crucial in tropical regions because of their high intensity rainfall.

Rainfall rate statistics specified on a percent of time basis, that is the percent of time in a year or a month that the rain rate equals or exceeds a specific value is used in the rain attenuation prediction model. The ITU rain attenuation prediction method is based on $0.01 \%$ of a year rain rate parameter ${ }^{[2]}$. Rain attenuation is caused by the overall rainfall intersecting the propagation path. This is usually modeled as the integration of the specific attenuation (attenuation per unit of distance) along the path. This integration has an impact on the dynamics of rain attenuation and although it has long been recognized, only a few models have been proposed ${ }^{[3]}$.

Since majority of the studies on Earth-space propagation have been conducted on Europe and the United States the existing prediction models may not be sufficiently accurate to characterize the effects of attenuation on tropical and equatorial climates. Under such circumstances, an evaluation of the prediction accuracy of these models is strongly required with a view to designing reliable satellite communication systems.
Rainfall rate and attenuation models

ITU-R rainfall rate model: The ITU model divides the world into 14 rainfall climatic zones and estimates the mean cumulative distribution based on the best available experimental data. Therefore the rainfall rate $R_{p}$, exceeded for different percentage of time is shown in Table $1^{[4]}$.

Table 1: Annual cumulative rain rate distribution for region $\mathrm{P}$

\begin{tabular}{lllll}
\hline Percentage of time, $\%$ & 0.3 & 0.1 & 0.01 & 0.001
\end{tabular}

Rainfall rate exceeded, $\mathrm{mm} / \mathrm{h} \quad 16.5 \quad 41.6 \quad 120 \quad 200$

Table 2: Annual cumulative rain rate distribution for region $\mathrm{H}$

\begin{tabular}{lllll}
\hline Percentage of time, $\%$ & 0.3 & 0.1 & 0.01 & 0.001
\end{tabular}

Rainfall rate exceeded,mm/h $\quad 31 \quad 51 \quad 147 \quad 251$

VIHT rainfall rate model: The model divides the world into eight regions based on total rain accumulation and the number of thunderstorm days from maps published by Landsberg ${ }^{[5]}$. The U.S is covered by five regions, but one of them is further divided into three sub regions. Crane obtained additional guidance from Koppen world climate classification. Boundaries were adjusted to accommodate variations in terrain, predominant storm type and motion, general atmospheric circulation and latitude. The measured $1 \mathrm{~min}$ rain rate distribution that were available for each of the seven regions and three sub regions were pooled to construct the rain rate distributions ${ }^{[6]}$. Malaysia is in region $\mathrm{H}$ and its cumulative rain rate distribution is given in Table 1.

ITU rainfall attenuation model: The ITU rainfall attenuation prediction model is based on determining the attenuation for $0.01 \%$ of time point rainfall rate at

Corresponding Author: Mandeep Singh Jit Singh, School of Electrical and Electronic Engineering, University Science Malaysia, 14300 Nibong Tebal, Seberang Perai Selatan, Penang, E-mail:mandeep_s75@yahoo.com 
$0.01 \%$ of time and then scaling this to the other time percentages ${ }^{[2]}$. The model is given as:

$\mathrm{A}_{\mathrm{p}}=\mathrm{A}_{0.01}(\mathrm{p} / 0.01)^{-\left(0.655+0.033 \ln (\mathrm{p})-0.045 \ln \left(\mathrm{A}_{0.01}\right)-\mathrm{z}(1-\mathrm{p}) \sin \theta\right)}$

DB

where $p$ is the percentage probability of interest, $\theta$ is antenna elevation angle, $\phi$ is the latitude of the earth station and $\mathrm{z}$ is given by

for $\mathrm{p} \geq 1 \%, \mathrm{z}=0$

for $\mathrm{p}<1 \%$,

$\mathrm{z}=0 \quad$ for $|\phi| \geq 36^{0}$

$z=-0.005\left(|\phi|-36^{0}\right)$ for $\theta \geq 25^{\circ}$ and $|\phi|<36^{0}$

$\mathrm{z}=-0.005\left(|\phi|-36^{\circ}\right)+1.8-4.25 \sin \theta$, for $\theta<25^{\circ}$ and $\mid$

$\phi \mid<36^{0}$.

$\mathrm{A}_{0.01}$ is attenuation exceeded for $0.01 \%$ of an average year is obtained from

$\mathrm{A}_{0.01}=\gamma_{\mathrm{R} 0.01} \mathrm{~L}_{\mathrm{e}} \mathrm{dB}$

whereby

$\gamma_{\mathrm{R} 0.01}=0.02\left(\mathrm{R}_{0.01}\right)^{1.2} \mathrm{~dB} / \mathrm{km}$

and

$\mathrm{L}_{\mathrm{e}}=\mathrm{L}_{\mathrm{r}} /\left\{1+\sqrt{\sin \theta}\left[31\left(1-\mathrm{e}^{-(\theta /(1+\chi)}\right)\right.\right.$

$\left.\left.\sqrt{\mathrm{Lr} \gamma / \mathrm{f}^{2}}-0.45\right]\right\} \mathrm{km}$

whereby, $\mathrm{f}$ is the operating frequency and

$\chi=36-|\phi| \quad$ for $|\phi|<36^{0}$

$\chi=0 \quad$ for $|\phi| \geq 36^{0}$

$\mathrm{L}_{\mathrm{g}} \mathrm{rh}_{0.01} / \cos \theta \quad \mathrm{km} \quad$ for $\zeta>\theta$

$\mathrm{L}_{\mathrm{r}}=$

$\left(\mathrm{h}_{\mathrm{fr}}-\mathrm{h}_{\mathrm{s}}\right) / \sin \theta \quad \mathrm{km} \quad$ for $\zeta \leq \theta$

where $\zeta=\tan ^{-1}\left[\left(\mathrm{~h}_{\mathrm{fr}}-\mathrm{h}_{\mathrm{s}}\right) /\left(\mathrm{L}_{\mathrm{g}} \mathrm{rh}_{0.01}\right)\right]$, polarization angle (degrees) and

$\mathrm{rh}_{0.01}=1 /\left[1+0.78 \sqrt{\operatorname{Lg} \gamma_{R 0.01} / \mathrm{f}}\right.$

$\left.-0.38\left(1-\exp \left(-2 \mathrm{~L}_{\mathrm{g}}\right)\right)\right]$

$\mathrm{h}_{\mathrm{fr}}$ is the freezing height during rain.

$\mathrm{h}_{\mathrm{s}}$ altitude of the earth station above sea level.

$\mathrm{L}_{\mathrm{g}}$ horizontal projection of the slant path length.

VIHT rainfall attenuation model: The VIHT model is based upon fact that the effective height of the attenuating medium changes depending on the type of rainfall event ${ }^{[7]}$. According to the VIHT model, the total path attenuation due to rain $\mathrm{A}[\mathrm{dB}]$ is given by,

$\mathrm{A}=\underline{\mathrm{aR}}_{\mathrm{p}}^{\mathrm{b}}-\underline{\mathrm{e}^{\mathrm{bUZ}}-1}-\underline{\mathrm{X}^{\mathrm{b}} \mathrm{e}^{\mathrm{bYZ}}}+\underline{\left.\mathrm{X}^{\mathrm{b}} \mathrm{e}^{\mathrm{bYD}}\right]}$

(bcos $\square$ ) U Y Y

Article I.

where $a=0.02$ and $b=1.179, \theta$ is the elevation angle $R_{p}$ is the rain rate and $\mathrm{D}$ is the horizontal projection length of the slant path length. The remaining coefficients $U$, $\mathrm{X}, \mathrm{Y}$ and $\mathrm{Z}$ are empirical constants that depend on $\mathrm{R}_{\mathrm{p}}$. $\mathrm{U}=1 / \mathrm{Z}\left(\mathrm{e}^{\mathrm{YZ}} \ln \mathrm{X}\right)$

$\mathrm{X}=2.3 \mathrm{R}_{\mathrm{p}}^{-0.17}$

$\mathrm{Y}=0.026-0.03 \ln \mathrm{R}_{\mathrm{p}}$

$\mathrm{Z}=3.8-0.6 \ln \mathrm{R}_{\mathrm{p}}$

Experimental set-up: The receiver site is located on the roof top of the electrical and electronic school of
USM in Nibong Tebal, at $5.17^{\circ} \mathrm{N}$ and $100.4^{0} \mathrm{E}$. The antenna elevation angle is approximately $40.1^{\circ}$ and the station height above sea level is $57 \mathrm{~m}$. The receiver antenna has a diameter of $2.4 \mathrm{~m}$. The receiver antenna is pointed towards SUPERBIRD C, located at $144^{\circ} \mathrm{E}$. The beacon frequency is $12.255 \mathrm{GHz}$ and it horizontally polarized. The tipping bucket rain gauge with $0.5 \mathrm{~mm}$ capacity and 1 minute integration of time is placed near the antenna.

\section{RESULTS AND DISCUSSION}

Figure 1 and 2 shows a comparison between proposed regional rain rate and attenuation characteristics based on the measured data and estimated rain rate and attenuation values using ITU and VIHT predictions models.

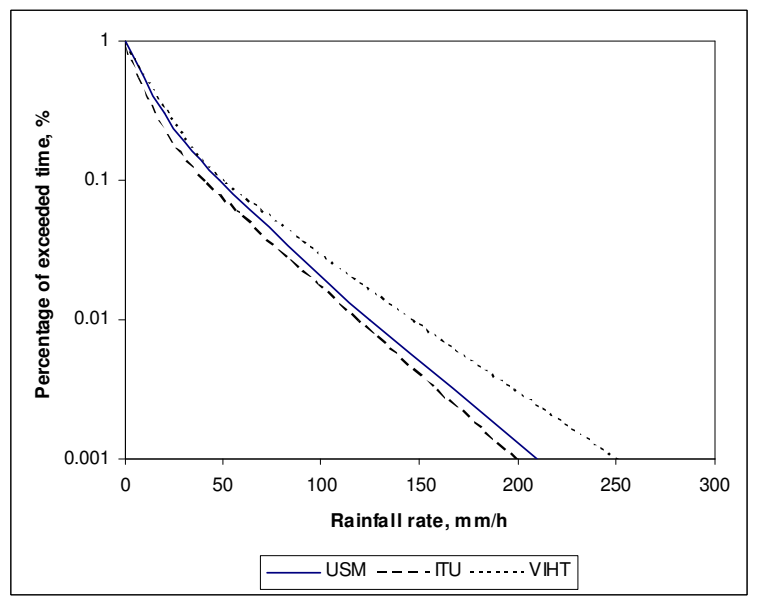

Fig. 1: Comparison of rainfall rate model with measured data

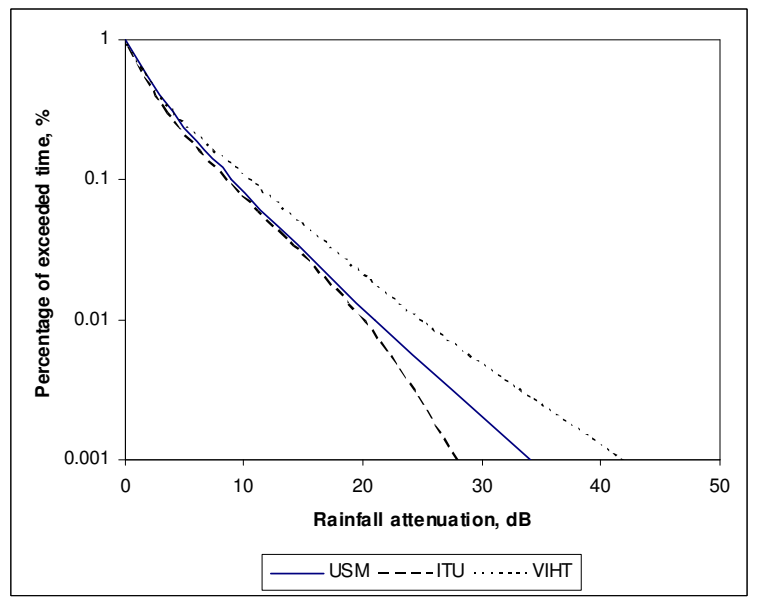

Fig. 2: Comparison of rainfall attenuation model with measured data

From Fig. 1 the ITU model approximates closely the measured rainfall rate throughout the entire percentage of time compared to the VIHT model which 


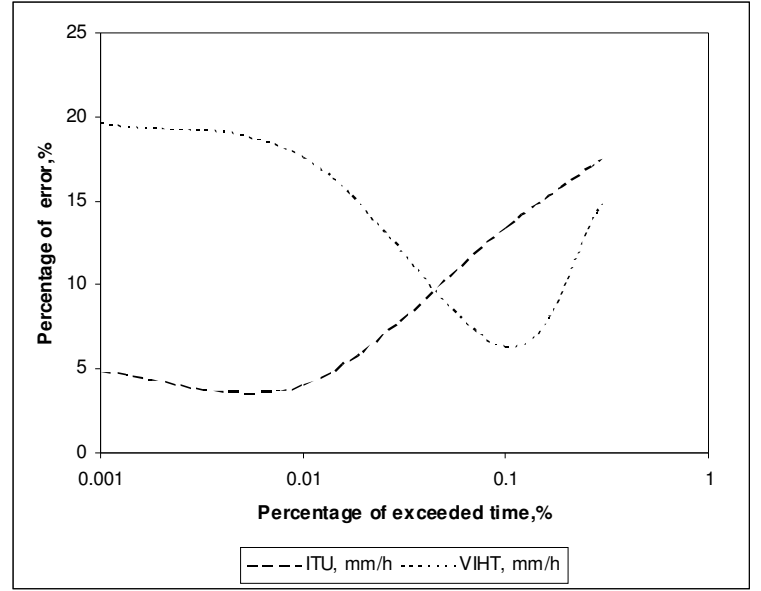

Fig. 3: Percentage error of each model for rainfall rate

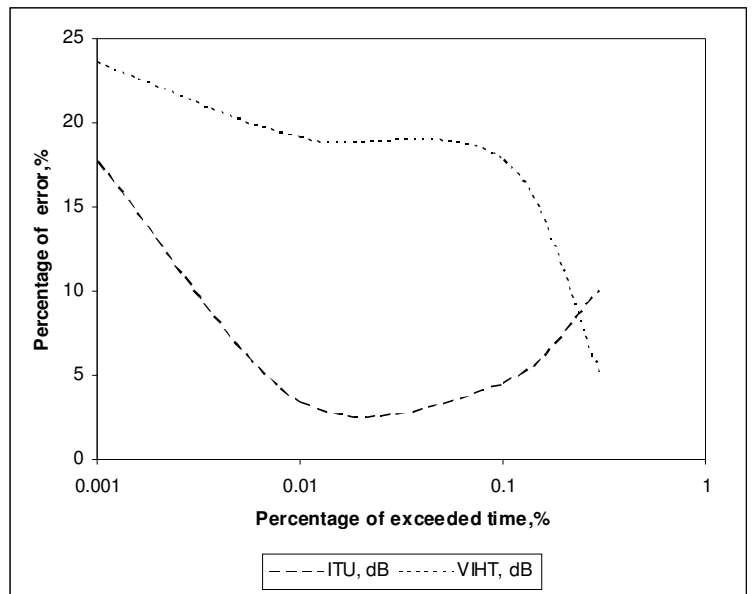

Fig. 4: Percentage error of each model for rainfall attenuation

overestimates the measured rainfall rate values. From Fig. 2 shows that only the VIHT the model overestimates the measured rainfall rate throughout the entire measurement time whereas the ITU model follows closely to the measured rainfall attenuation data until $0.01 \%$ of time before the model starts to underestimate.

Figure 1 shows that the percentage error for the ITU model is below $10 \%$ from $0.03 \%$ of time to $0.001 \%$ of time and the VIHT model has a percentage error below $10 \%$ at $0.1 \%$ of time. The percentage error for VIHT increases as the percentage of time gets lower.

Figure 4 shows that the ITU model has a percentage error below $10 \%$ from $0.3 \%$ to $0.003 \%$ of time whereas the VIHT model's percentage error increases as the percentage of exceeded time gets lower. The VIHT model reaches to an error of $24 \%$ at $0.001 \%$ of time.

The ITU model has a roll-over effect from $0.003 \%$ to $0.001 \%$ of time, where as the rainfall rate increases, the attenuation reduce. This is because of the lack of high rainfall rate data from Tropical and Equatorial climate. The vertical path reduction coefficient was used to minimize the prediction error.

For the VIHT model, the rainfall attenuation prediction procedure assumes a monotonic relationship between the rainfall rate cumulative distribution and the equiprobable values in the attenuation cumulative distribution. The model did not introduce the vertical reduction factor to reduce the prediction error.

\section{CONCLUSION}

In this paper the regional rainfall attenuation and rainfall rate for USM were compared to ITU and VIHT prediction models. Overall the ITU rainfall rate and attenuation model gave a good prediction and the VIHT model was found to be not suitable for prediction at tropical and equatorial climates.

\section{ACKNOWLEDGMENT}

The author would like to thank University Science Malaysia for carrying out the experiment and also the POST-PARTNERS promotion Council for their dedicate support and providing the equipment to University Science Malaysia.

\section{REFERENCES}

1. Maseng, T. and P.M. Bakken, 1981. A stochastic dynamic model of rain attenuation. IEEE Trans. on Comm., 29: 660-669.

2. ITU-R P.618-7. Propagation Data and Prediction Methods Requirement for the Design of EarthSpace Telecommunication System, 2001.

3. Manning, R.M., 1990. A unified statistical rainattenuation model for communication link fade predictions and optimal stochastic fade control design using a location-dependent rain-statistic database. Intl. J. Satellite Commun., 8: 11-30.

4. ITU-R Study Group 3 Databank. http://www.itu.int/ ITU-R/software /studygroups/rsg3 /databanks/ troposph/rec837/, 2002.

5. Landsburg, H.E., 1974. "World survey of Climatology. Vol. 1-15. Amsterdam, The Netherlands: Elsevier.

6. Tattelman, P. and D.D. Grantham, 1985. A review of models for estimating $1 \mathrm{~min}$ rainfall rates for microwave attenuation calculations. IEEE Trans. on Comm., COM-33: 361-372.

7. Hasanuddin, Z.B., K Ishida, K. Fujisaki and M. Tateiba, 1993. The comparison of the measurement of rain attenuation in ku- band satelliet channel and estimation of VIHT and CCIR ethods. Kyushu University. 